\title{
Influence of moisture on maturation rate of the Venturia inaequalis (Cooke) Wint. ascospores in central Poland
}

\author{
Paweł Jankowski ${ }^{1}$ (D) Sylwester Masny ${ }^{2}$
}

Received: 8 October 2018 / Accepted: 5 October 2019 / Published online: 18 October 2019

(c) The Author(s) 2019

\begin{abstract}
Influence of moisture on maturation rate of the airborne Venturia inaequalis (Cooke) Wint. ascospores was numerically examined using field data collected from spore traps in Skierniewice, Poland, during 2005-2008 and 2010-2014. In order to avoid a bias resulting from different abundance of airborne ascospores in different seasons, the cumulative proportions of mature ascospores observed in the season were analyzed. The maturation rate was expressed with the probit of cumulative proportion which linearized its sigmoidal shape and made the effect of the weather during the entire season of the same importance. The significant, positive association between the probit slope and the moisture indicators related to precipitation, leaf wetness, and high relative humidity were observed. Additionally, the significant, negative relationships with the average and maximal air temperature were found. The results suggested that rain should be treated as the major factor driving the ascospore development and leaf wetness as the second factor. In conclusion, the main sources of moisture should be taken into account in statistical models of ascospore development, but it seems reasonable to take into account different strength of their association with the development rate.
\end{abstract}

Keywords Venturia inaequalis $\cdot$ Apple scab · Ascospore maturation $\cdot$ Statistical model $\cdot$ Temperature accumulation $\cdot$ Influence of moisture

\section{Introduction}

Apple scab, caused by the fungal pathogen Venturia inaequalis (Cooke) Wint., is the most harmful apple disease in temperate regions throughout the world (MacHardy 1996). $75 \%$ of the pesticide use in apple production is related to the control of fungal diseases, where apple scab has a share of $70 \%$ (Creemers and van Laer 2006), applied in a few to over a dozen fungicide treatments in the growing season.

There are various approaches to limit the number of sprays in modern orchards. The key one is to reduce overwintering inoculum by autumn mulching or ranking leaves in the orchard. The other approach is based on the predictions of the $V$. inaequalis ascospore releases. Fungicide

Paweł Jankowski

pawel_jankowski@sggw.pl

1 Institute of Information Technology, Warsaw University of Life Sciences - SGGW, Ul. Nowoursynowska 159, 02-776 Warsaw, Poland

2 Research Institute of Horticulture, Ul. Pomologiczna 18, 96-100 Skierniewice, Poland programs or models estimating the risk of infection have been developed on the basis of this approach (Gadoury et al. 1989; Rossi et al. 2007). In order to predict the ascospore releases, their seasonal maturation pattern is described with the use of mathematical models. From the beginning of modeling of the ascospore development dynamics, various authors recognized that it is accelerated by moisture present in the orchard (Massie and Szkolnik 1974; James and Sutton 1982a). Mathematical models of ascospore maturation, in different ways taking into account the influence of moisture, have been developed and examined by many groups of researchers in many countries (Massie and Szkolnik 1974; Gadoury and MacHardy 1982; James and Sutton 1982a, b; MacHardy and Gadoury 1985; St-Arnaud and Neumann 1990; Stensvand 1993; Beresford 1999; Rossi et al. 1999, 2000, Gadoury et al. 2004; Stensvand et al. 2005; Schwabe et al. 1989; Alves and Beresford 2013; Roubal and Nicot 2016). To date, no such investigation has been reported on from Poland.

In the current study, we wished to perform the first step in the modeling of ascospore maturation rate in central Poland. We wanted to assess the effect of various sources 
of moisture in an orchard on ascospore development avoiding two sources of possible bias. Firstly, we examined the cumulative proportions of mature ascospores observed to the present moment of the season, in order to avoid the influence of different overall numbers of ascospores observed in various seasons. Secondly, because the proportions of mature spores during a season form a sigmoidal function, the major increase in the percentage of the mature spores is observed in the central period of the season, while the increase in the beginning and the end of the season is less important and so may seem the effect of the weather in that periods. In order to examine the influence of the moisture during the entire seasons under investigation, we applied the probit function, which linearizes the sigmoidal shape and makes the effect of the weather during the entire seasons of the same importance.

The first goal of the study was to present the main approach to mathematically model the influence of moisture on development of ascospores. The second, most important aim was to estimate the strength of the association of chosen weather factors with the maturation rate of ascospores in central Poland, using long-term experimental data. The novel approach to this issue, applied in the study, based on relating the slope coefficient of the probit of cumulative proportion of mature ascospores observed in the season with the chosen weather descriptors: air temperature and indicators of moisture. The indicators of moisture considered were the rainfall, leaf wetness, and the relative air humidity.

\section{Materials and methods}

\section{Ascospore trapping and weather data}

The experiment was conducted at the Experimental Orchard of the Research Institute of Pomology and Floriculture in Skierniewice, Poland (N 51 ${ }^{\circ} 55^{\prime}$; E 20 $0^{\circ}$ ) in the years 2005 to 2014. Air temperature, precipitation, relative humidity (RH) and leaf wetness (LW) were recorded by an automatic weather station (model Metos-Compact, Pessl Instruments, Weiz, Austria) placed at the experimental site. The LW data are the result of the leaf wetness simulation by the sensor. Analysis of graphs of weather factors in each year suggested incorrect measurements of the leaf wetness sensor in the season 2009. Therefore, data from the year 2009 were excluded from the analysis.

A Burkard 7-day recording volumetric spore trap (Burkard Manufacturing Co Ltd., Rickmansworth, Hertfordshire, UK) was used to monitor the release of ascospores. Approximately $2 \mathrm{~m}^{2}$ of the orchard floor under the Burkard sampler were covered with leaves of the apple cultivar McIntosh heavily infected with $V$. inaequalis the previous season. The trees were not treated with fungicides during the experiment and for the preceding 10 years. The spore trap was installed in the center of this area and was adjusted to sample the air $1 \mathrm{~m}$ above the ground at a sampling rate of $0.6 \mathrm{~m}^{3} \mathrm{~h}^{-1}$. The tape from the Burkard trap, covered with a thin layer of Gelvatol and Vaseline, was changed weekly and cut into daily segments (48 mm long), which were then mounted on glass slides with a double-stick tape. The number of $V$. inaequalis ascospores deposited on the sampling surface was counted under a microscope $(200 \times)$ by scanning two equidistant transects across the tape's long axis at 2-mm intervals, which corresponded to a time interval of $1 \mathrm{~h}$.

The ascospore discharge seasons in the years 2005-2008 and 2010-2014 lasted from 43 to 93 days with the first and last dates of spore releases varying from 12 March to 19 April and from 29 May to 17 June, respectively. The ascospores were trapped during 21 to 33 days of a season, giving in total 236 discharges.

\section{Mathematical description of Venturia inaequalis (Cooke) Wint ascospore maturation}

The numbers of mature ascospores in the experimental orchard were approximated with the numbers of airborne ascospores trapped during consecutive discharges with a Burkard-type trap (Rossi et al. 1999; Lacey and West 2006). The spores, which by being released into the air could lead to apple scab infection in the orchard, were accepted as mature.

The mathematical model of ascospores' development applied in the study describes the cumulative proportion (percentage) $p$ of mature ascospores observed to the present moment of the season to the total number of ascospores trapped during the entire season. The value of the proportion smoothly changes from 0 in the beginning of the season to 1 in its end. The proportion $p$ was expressed as a function of cumulative temperature, $T_{\text {cum }}$, calculated as the sum of all positive temperatures counted from the starting date referred to as biofix. The biofix was established as the beginning of the first ascospore release. The hourly timescale was applied, so the $T_{\text {cum }}$ and the numbers of observed ascospores were calculated for each hour of the season.

The dependence of the proportion of mature ascospores on the cumulative temperature $p\left(T_{\text {cum }}\right)$ is described with a function of a sigmoidal shape. In the presented study, it was modeled with the probit function (Massie and Szkolnik 1974; Gadoury and MacHardy 1982; Stensvand et al. 1998a; 2005):

$\operatorname{probit}\left(p\left(T_{\text {cum }}\right)\right)=\operatorname{probit}\left(T_{\text {cum }}\right)=\Phi^{-1}\left(p\left(T_{\text {cum }}\right)\right)$,

where $\Phi^{-1}$ is the inverse of the cumulative distribution function of the standard normal distribution. The use of the probit function has an important advantage. It converts the 
sigmoidal shape of the $p\left(T_{\text {cum }}\right)$ function into a linear function of the cumulative temperature:

$\operatorname{probit}\left(T_{\text {cum }}\right)=\beta_{0}+\beta_{1} \cdot T_{\text {cum }}$.

The numerical values of the $\beta_{0}$ and $\beta_{1}$ coefficients can be matched to the experimental data with the simple linear regression. These coefficients have a very simple interpretation: $\beta_{0}$, or intercept, is the value of the function probit $\left(T_{\text {cum }}\right)$ at the point $T_{\text {cum }}=0$, while $\beta_{1}$, the slope coefficient, defines the inclination angle (slope) of the line representing the probit function. The higher the value of $\beta_{1}$, the higher the inclination angle which corresponds to the faster ascospore maturation.

\section{Assessing the effect of moisture on Venturia inaequalis (Cooke) Wint ascospore maturation}

An exemplary result of the probit model of ascospore development, for the data from the year 2007, is presented in Fig. 1. The plot presents also result of a model of the data using, instead of one, a series of probit functions:

$\operatorname{probit}_{i}\left(T_{\text {cum }}\right)=\beta_{0, i}+\beta_{1, i} \cdot T_{\text {cum }}$,

each between a succeeding, $i$ th, pair of ascospore releases. The fit of this model is the same as the result of linear interpolation of consecutive ascospore release events. Changes of the inclination angle (or $\beta_{1, i}$ values) of the probit functions

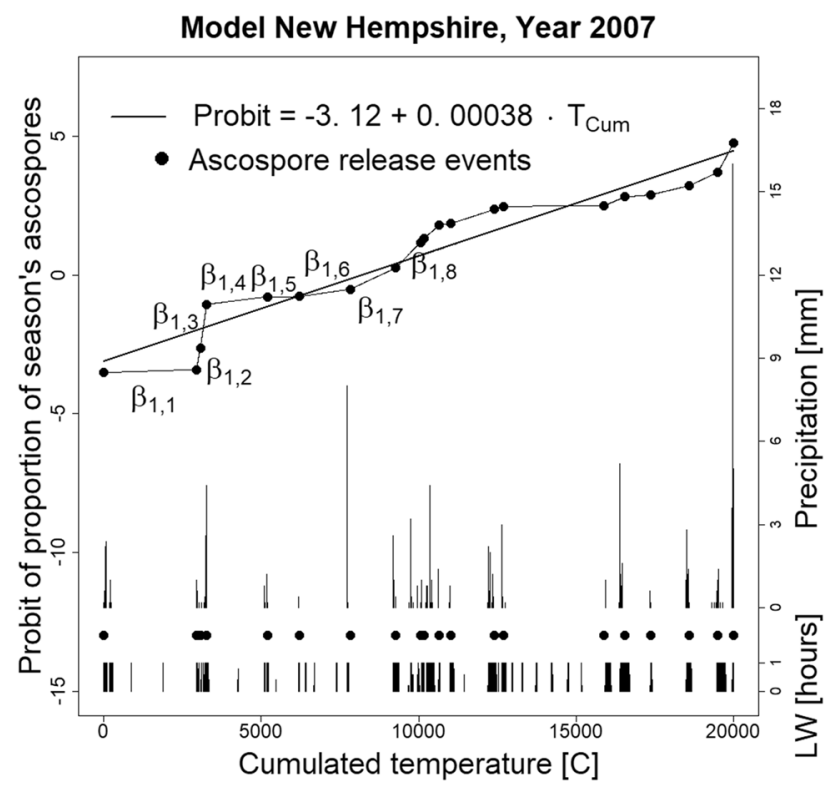

Fig. 1 An exemplary result of modeling of ascospore development with the probit function, for the data from the year 2007 (straight line). The polygonal curve presents result of a model, using a series of probit functions, each for a succeeding, $i$ th pair of ascospore releases: the slope coefficient of each of the functions is denoted as $\beta_{1, i}$. The periods of precipitation and leaf wetness shown on the plot indicate a different rate of ascospore development which may result from different weather conditions. Hence, testing the dependence of the $\beta_{1, i}$ values on weather between ascospore releases can give information on the impact of weather on ascospore maturation rate.

\section{Statistical analysis}

The probit function of the cumulative proportion of mature ascospores was computed according to formula (3) for each of 227 pairs of succeeding ascospore releases in the years 2005-2008 and 2010-2014. As a result, 227 slope coefficients, $\beta_{1, i}$, were computed. Next, for each pair of succeeding ascospore discharges, the average and the maximal temperature and the chosen moisture descriptors were calculated. In order to assess the influence of weather on the rate of ascospores development in the periods between their releases, relations between the calculated $\beta_{1, i}$ values and corresponding weather descriptors were examined.

As the examined data show high heteroskedasticity, the regression analysis could not be applied. Therefore, for each weather descriptor, a contingency table of the $\beta_{1, i}$ values versus the descriptor values were calculated. First, the equal frequency binning into five categories was applied separately for both, the slope coefficient and the weather descriptor. Next, the computed bin boundaries were used to cross-tabulate the variables. As the parallel line assumption was violated for most of the weather descriptors, the ordered logit regression method could not be applied to the data. Because, after binning, both the $\beta_{1}$ and the weather descriptors are the ordinal categorical variables, the strength of association between them was assessed with the Kendall tau-b and the Goodman and Kruskal's Gamma coefficients. In each assessment, we calculated the strength of association between the probit slope coefficient $\beta_{1}$ and a different weather descriptor, basing on their contingency tables. Additionally, three-way cross-tabulation and the partition of the Marcotorchino tau index was applied to simultaneously examine the association between the $\beta_{1}$ coefficient and two weather descriptors, all treated as the ordinal variables (Beh et al. 2007). In this case, in order to avoid empty cells in the calculated contingency tables, each variable was binned into three categories.

All analyzes presented in the study were performed in the $R$ program version 3.5.3 (R Core Team 2016) with the use of RStudio version 1.1.463 (RStudio Team 2015).

\section{Results and discussion}

In the presented study, the effect of various sources of moisture on the ascospore maturation rate was analyzed by relating the values of the probit slope coefficient $\beta_{1}$ computed separately for each pair of succeeding ascospore discharges 
with the chosen descriptors of weather in a period between these discharges. All temperatures were accumulated irrespective of the prevailing weather in order to relate temperature accumulation to no particular weather conditions, and therefore do not introduce any bias on the examined relations. Additionally, instead of the usually applied daily timescale, the hourly scale was used as it should more accurately reflect the development of ascospores in response to changes in weather (James and Sutton 1982b).

In practice, the approach used usually to describe the ascospore maturation is to keep $\beta_{1}$ constant in formula (3) but to impose weather-related constraints on accumulation of temperature. In this approach cumulative temperature $T_{\text {cum }}$ increases only when the chosen moisture indicators show the weather conditions conducive to the development of ascospores. Otherwise accumulation of temperature is halted. Various indicators of moisture were used in the literature in order to describe the influence of moisture on rate of ascospore development.

The most obvious indicator of moisture is precipitation which was applied, among others, in models by Massie and Szkolnik (1974), James and Sutton (1982b), Stensvand et al. (1998a, 2005) and Rossi et al. (1999). Experiments by James and Sutton (1982a) showed that high relative humidity (RH) can be an additional to the rain source of moisture, which can lead to ascospore development. Therefore, in the model proposed by James and Sutton (1982b), the ascospores mature provided that daily rain is at least $0.25 \mathrm{~mm}$ and/or the number of hours of the day with RH equal to $100 \%$ exceeds 12. Similar model was proposed by Rossi et al. (1999): a model in which the temperatures of rainy days and of the days when RH equals or exceeds $85 \%$ for at least $8 \mathrm{~h}$ were accumulated. Additionally, the same authors examined a model in which rain or observed dew deposition signals temperature accumulation (Rossi et al. 1999). Finally, they proposed a model, in which the temperature is accumulated only if the leaf wetness is observed, irrespective of the rain. This approach was further studied (Rossi et al. 2000) and applied in the A-scab, a simulation model for estimating risk of $V$. inaequalis primary infections (Rossi et al. 2007).

In the current study, we examined the association of the spore maturation rate with the moisture indicators related to rain: total rainfall, number and share of rainy hours, and average precipitation per hour; leaf wetness duration: number and share of hours with observed leaf wetness periods (LW $>0)$; and relative humidity: average RH and number and share of hours with high ( $\mathrm{RH} \geq$ minimal humidity tested in the range from 80 to $90 \%$ ). Additionally, the effect of temperature was examined using the average and the maximal temperature between each pair of succeeding ascospore discharges.

Relations between each weather descriptor and $\beta_{1}$ were examined independently. The assessment of the strength of association between the slope coefficient and each weather descriptor is presented in Table 1. Statistically significant relationships between $\beta_{1}$ and weather were shown for all indicators of moisture apart from the number of hours with high RH.

The results in Table 1 show higher correlation between the rate of ascospore maturation and the averaged values (mean values of rain or relative humidity and the shares of hours with favorable weather condition) than the absolute values (total rainfall and numbers of hours with rain, leaf wetness or high $\mathrm{RH}$ ). These results can be explained in the following way. In the study, we examine the average speed of ascospore maturation in the periods of time between the
Table 1 The Kendall tau-b and the Goodman and Kruskal's Gamma coefficients measuring the strength of association between the probit slope coefficient $\beta_{1}$ and the chosen weather descriptors

\begin{tabular}{|c|c|c|c|c|}
\hline \multirow[t]{2}{*}{ Weather descriptor } & \multicolumn{2}{|c|}{ Kendall tau-b } & \multicolumn{2}{|c|}{$\begin{array}{l}\text { Goodman ans Kruskal's } \\
\text { Gamma }\end{array}$} \\
\hline & Coefficient & $p$ value & Coefficient & $p$ value \\
\hline Total rain $(\mathrm{mm})$ & 0.371 & $3.65 \mathrm{e}-12$ & 0.454 & $9.20 \mathrm{e}-14$ \\
\hline Number of hours with rain $>0 \mathrm{~mm}$ & 0.390 & $4.04 \mathrm{e}-13$ & 0.483 & $1.22 \mathrm{e}-17$ \\
\hline Mean rain (mm) & 0.483 & $1.45 \mathrm{e}-19$ & 0.584 & $2.70 \mathrm{e}-27$ \\
\hline Share of hours with rain $>0 \mathrm{~mm}$ & 0.492 & $2.97 \mathrm{e}-20$ & 0.595 & $1.63 e-29$ \\
\hline Number of hours with LW $>0$ & 0.258 & $1.33 \mathrm{e}-06$ & 0.321 & $1.24 \mathrm{e}-07$ \\
\hline share of hours with $L W>0$ & 0.303 & $1.37 \mathrm{e}-08$ & 0.373 & $3.79 \mathrm{e}-10$ \\
\hline Mean RH (\%) & 0.244 & $4.73 e-06$ & 0.303 & $3.09 \mathrm{e}-06$ \\
\hline Number of hours with $\mathrm{RH} \geq 85 \%$ & 0.0144 & 0.787 & 0.0179 & 0.775 \\
\hline Share of hours with $\mathrm{RH} \geq 85 \%$ & 0.261 & $1.01 \mathrm{e}-06$ & 0.322 & $1.27 \mathrm{e}-06$ \\
\hline Mean temperature $(\mathrm{C})$ & -0.120 & 0.0243 & -0.149 & 0.0215 \\
\hline Maximal temperature (C) & -0.182 & 0.000664 & -0.225 & 0.000239 \\
\hline Share of hours with $L W>0$ and no rain & 0.195 & 0.000259 & 0.241 & $7.31 \mathrm{e}-05$ \\
\hline Share of hours with $\mathrm{RH} \geq 85 \%$ and no rain & 0.0614 & 0.250 & 0.0765 & 0.262 \\
\hline
\end{tabular}


ascospore releases. These periods have different length. It is reasonable to assume that if two periods have the same number of rainy hours (and therefore the same total rainfall) or hours with high $\mathrm{RH}$, the faster average ascospore maturation will be observed in the shorter one, with higher share of hours with favorable weather. Therefore, the average speed of ascospore maturation should be higher correlated with averaged values than the absolute values describing the weather conditions favorable for maturation of ascospores.

The rain-related descriptors, average precipitation per hour and share of rainy hours, showed overall highest association with $\beta_{1}$; see Fig. 2 for the share of rainy hours. Weaker association was found for the leaf wetness; see Fig. 3, and relative humidity used as the indicators of moisture, with the minimal humidity equal to $85 \%$ giving best results in the case of the share of hours with high RH; see Fig. 4. Hence, rain should be treated as the major factor driving the ascospore development. The RH limit equal to $85 \%$ agrees with the RH threshold used in models of ascospore maturation first by James and Sutton (1982b) and later by other authors (Schwabe et al. 1989; Rossi et al. 1999). On the other hand, for two reasons, a very precise choice of the RH limit does not seem crucial. Firstly, the values of the Kendall tau-b and the Goodman and Kruskal's Gamma coefficients for different RH limits in the range from 80 to $90 \%$ were very small. The Kendall tau-b values varied from
0.244 to 0.261 and values of the Goodman and Kruskal's Gamma coefficient varied from 0.292 to 0.322 . Secondly, the accuracy of RH measurement by the weather station is $\pm 3 \%$ within a range of $85 \%$ and $\pm 2 \%$ within a range of $85-96 \%$ which effects the precision of the established RH limit.

Weak, but significant relationship was found between the probit slope and the average temperature. Slightly stronger association was observed for the maximal temperature. As can be seen in Fig. 5, that result does not indicate that increase in the temperature generally leads to decrease in the ascospore maturation rate. The distribution of $\beta_{1}$ values is skewed with the maximum in the middle range of temperatures. Still, the results indicate that high temperatures are not favorable to ascospore discharges. The main indicators of moisture are closely related, as rainfall is usually accompanied with high RH and LW $>0$. During years 2005-2008 and 2010-2014, there were 1349 rainy hours, $3826 \mathrm{~h}$ with observed LW and $10,012 \mathrm{~h}$ with RH of at least $85 \%$. LW was observed during 90\% (1217) and $\mathrm{RH} \geq 85 \%$ during $94 \%$ (1262) of rainy hours, respectively. Therefore, the question is whether significant relations between ascospore maturation and shares of hours with observed leaf wetness and high relative humidity resulted only from correlation of these factors with the rain, or the LW and the high RH additionally accelerated the ascospore development on rainless hours. The associations were examined for two weather descriptors:

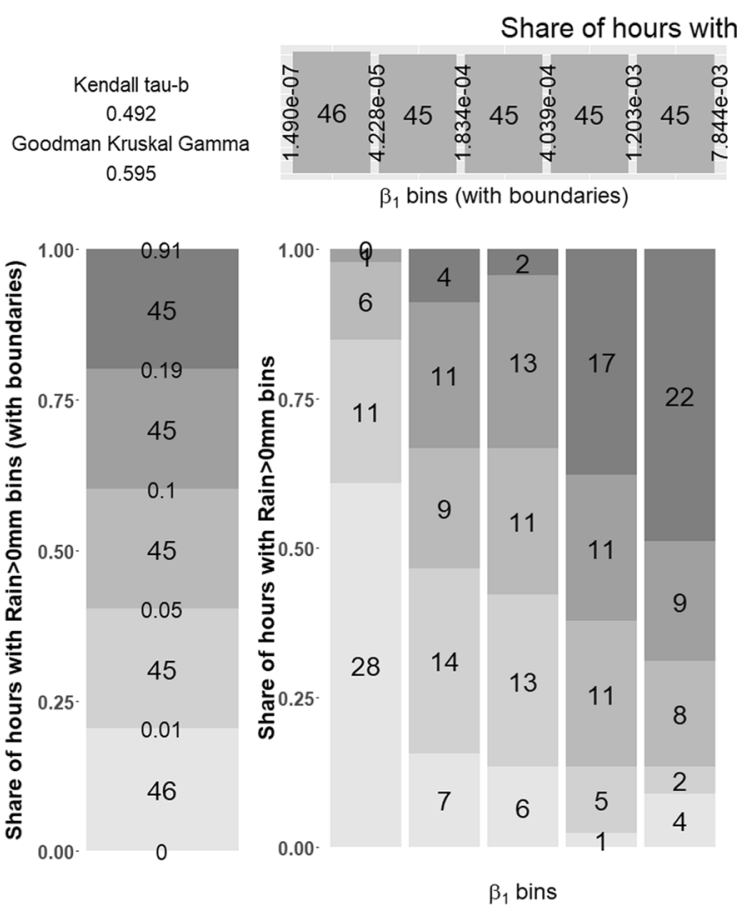

Fig. 2 The relationship between the probit slope coefficient $\beta_{1}$ and the share of hours with observed precipitation between ascospore releases. Left: graphical representation of the contingency table of the examined variables with the marginal totals and boundary values

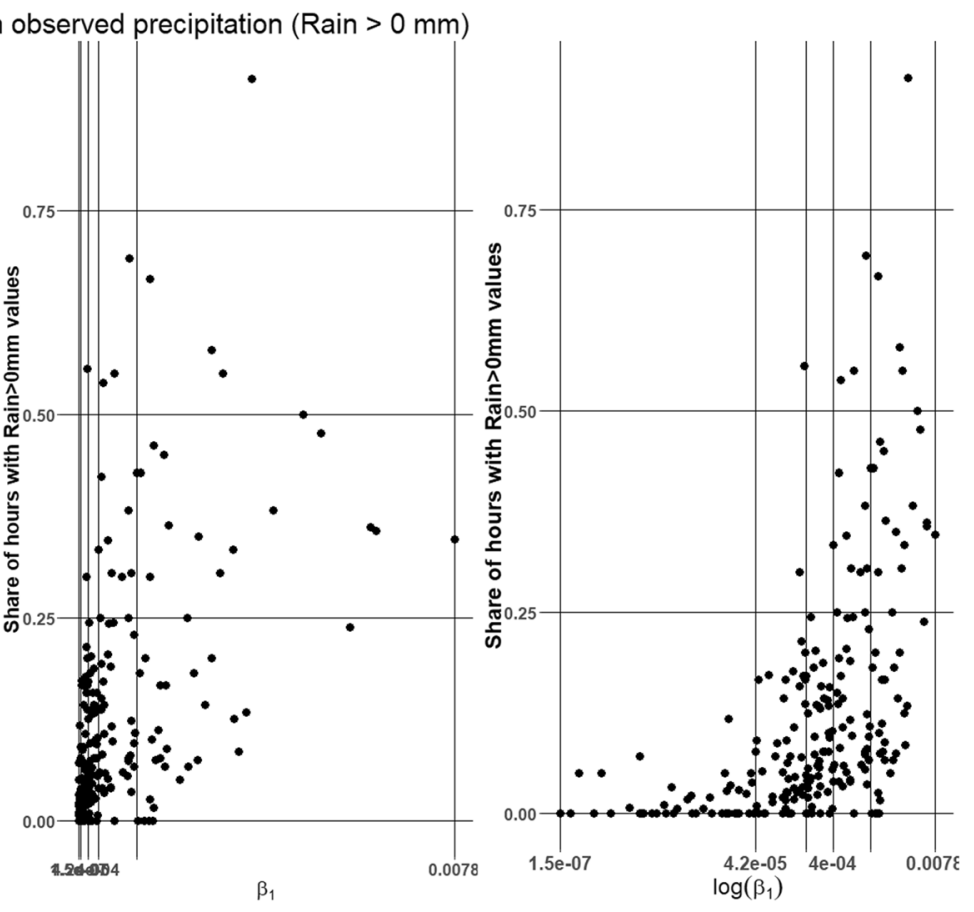

used to bin the data. Right: distribution of the examined data points with the lines marking the division of the data into bins. The points presented on the linear and logarithmic scale for the $\beta_{1}$ coefficient 


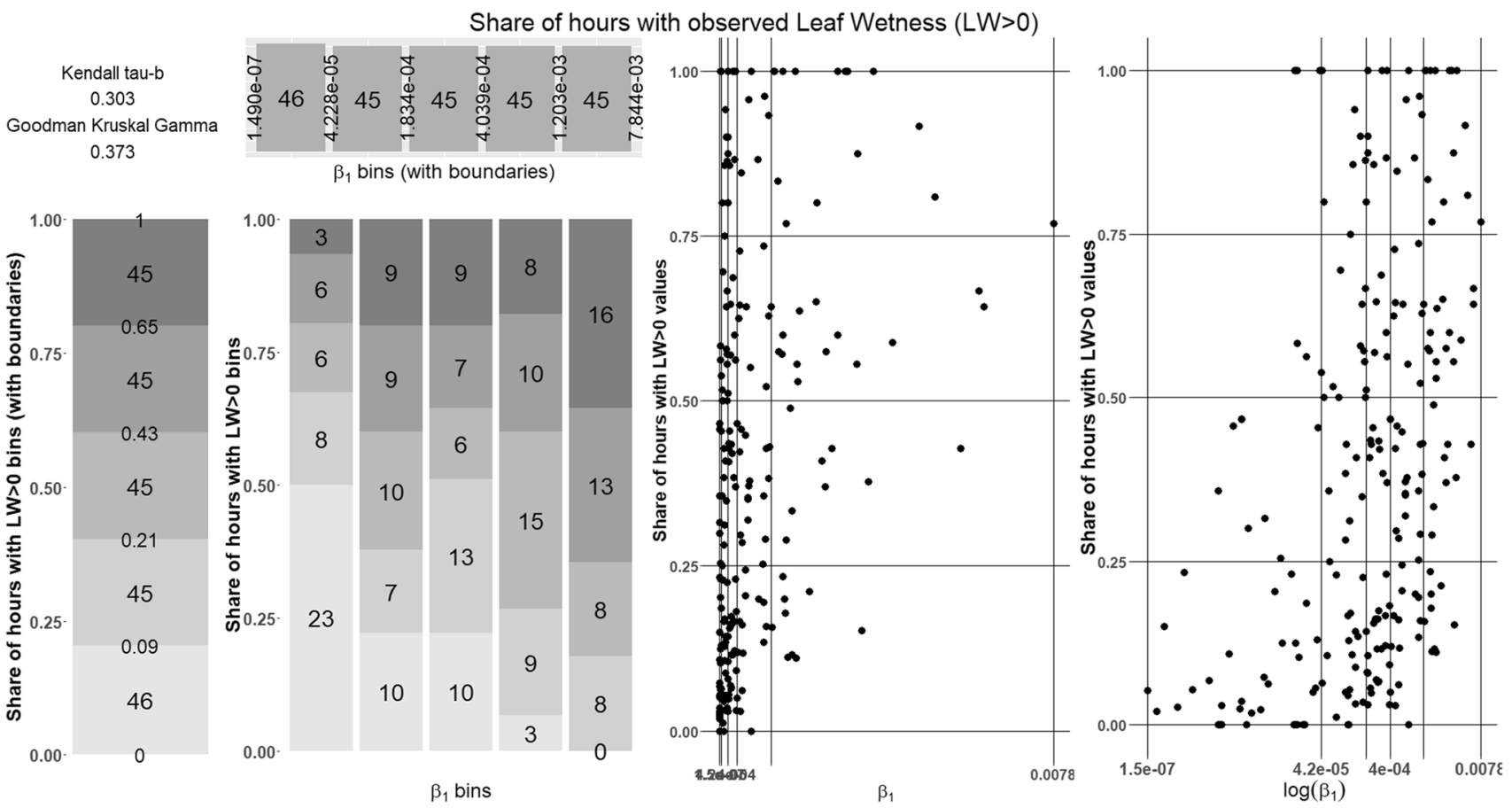

Fig. 3 Same as Fig. 2, for the share of hours with observed leaf wetness between ascospore releases

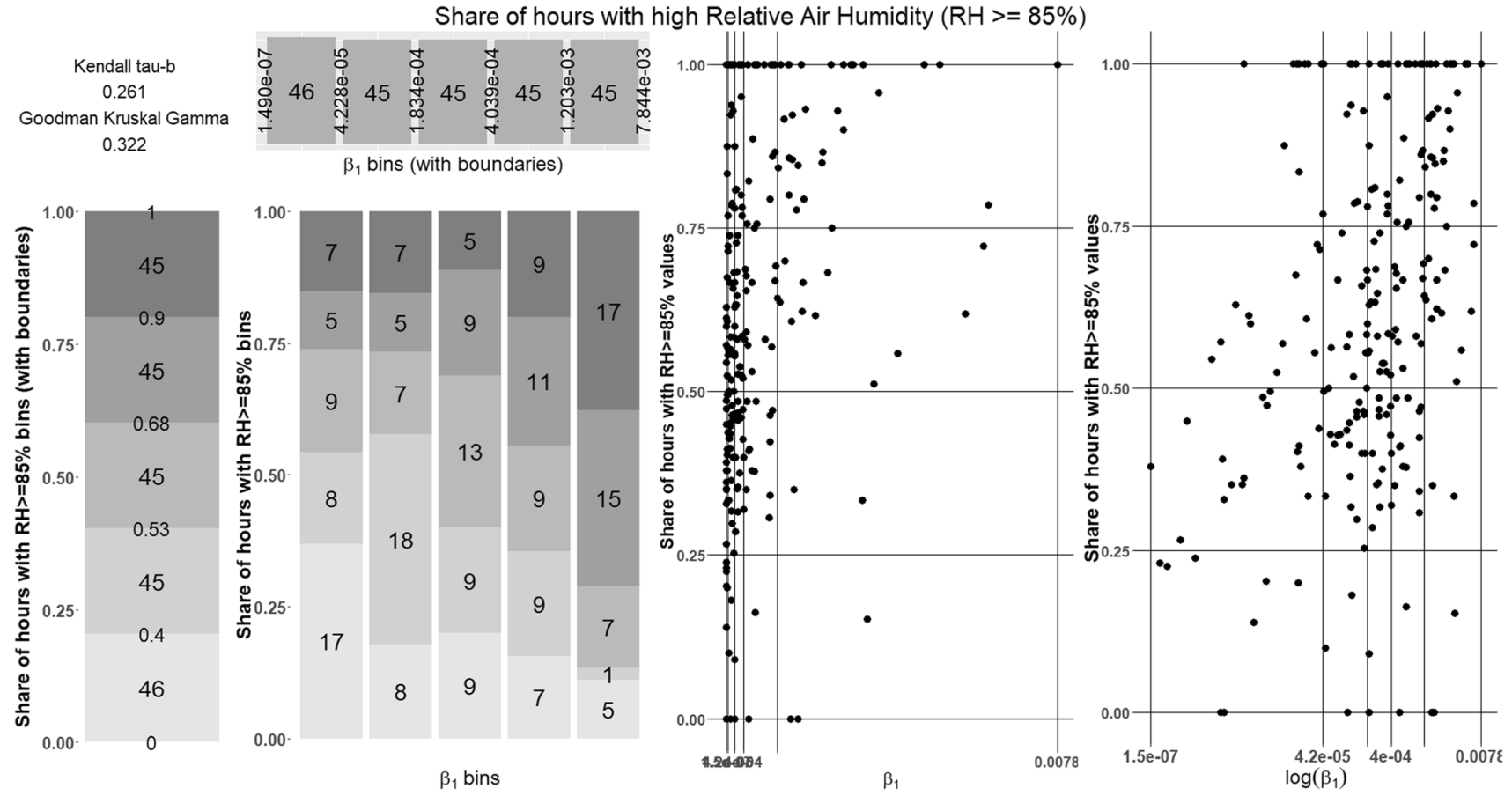

Fig. 4 Same as Fig. 2, for the share of hours with high relative air humidity (RH $\geq 85 \%)$ between ascospore releases

share of hours with LW $>0$ and without the rain observed, and share of hours with $\mathrm{RH} \geq 85 \%$ and without the rain observed. As shown in Table 1, only in the case of LW $>0$, a significant relation between $\beta_{1}$ and the weather descriptor was found; see also Fig. 6. 


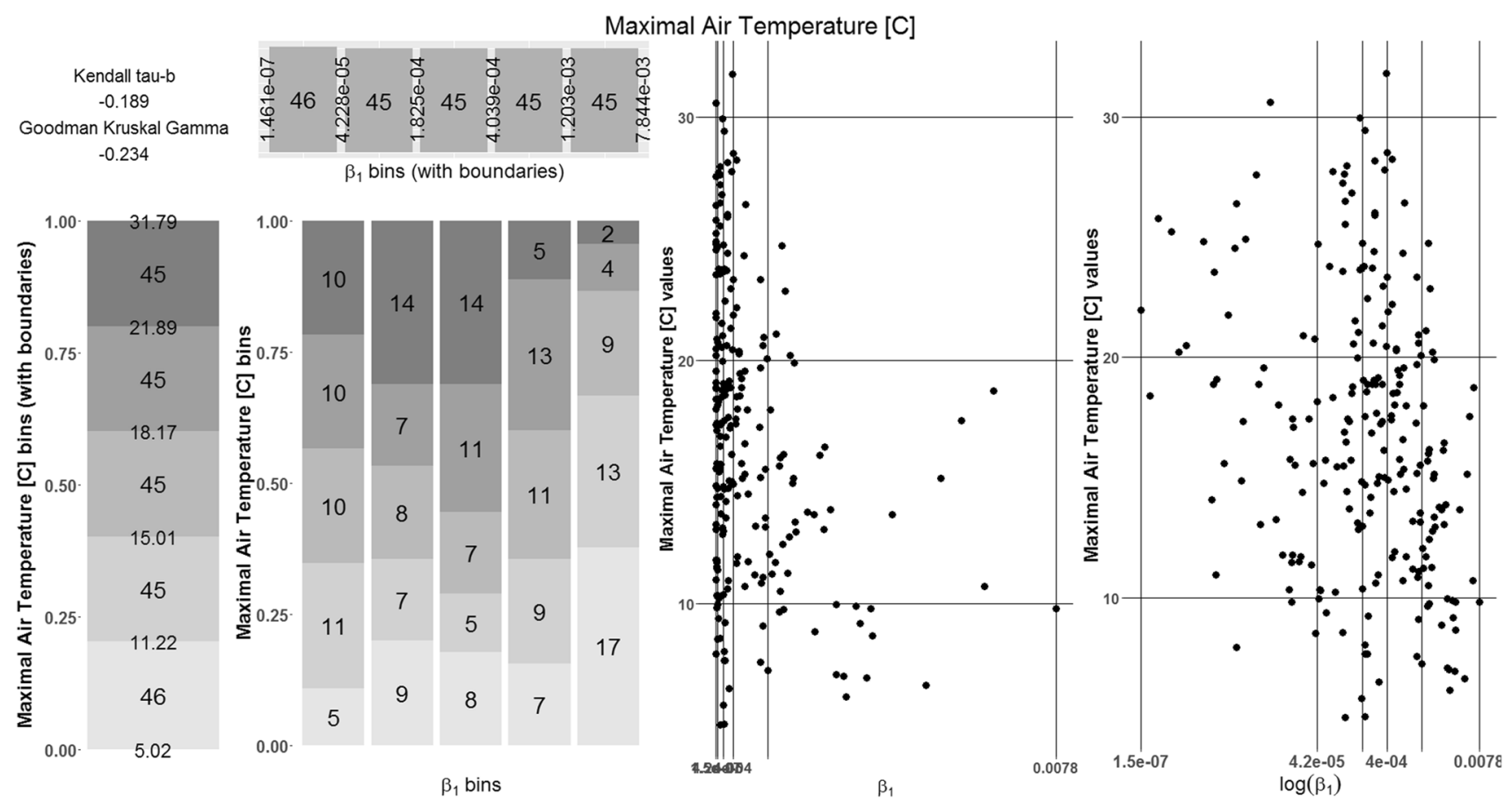

Fig. 5 Same as Fig. 2, for the maximal temperature between ascospore releases

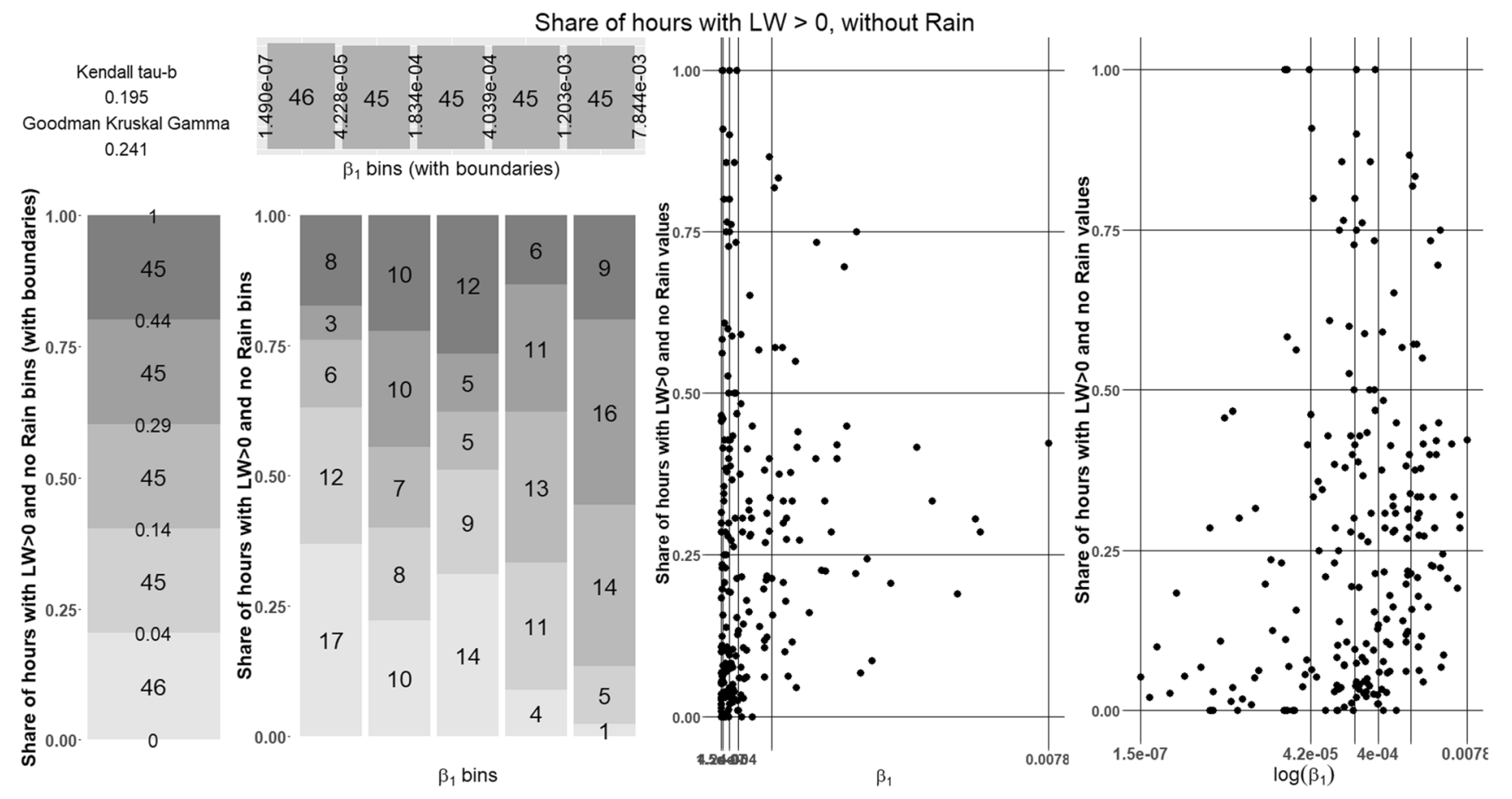

Fig. 6 Same as Fig. 2, for the share of hours with observed leaf wetness and with lack of precipitation between ascospore releases

Finally, the partition of the Marcotorchino tau index was computed for three variables: the probit slope coefficient $\beta_{1}$, the share of rainy hours, and the share of hours with
LW $>0$ but without the rain observed. The results showed that tau index equaled 0.319 and that both moisture indicators were significantly associated with the rate of ascospore 
maturation. The more influential variable was the share of rainy hours as it accounted for $51 \%$ of the total variation summarized by the Marcotorchino tau index and share of hours with LW $>0$ but without the rain accounted for $23 \%$ of the total variance. Analogous computation performed for $\beta_{1}$ coefficient, the share of rainy hours and the share of hours with $\mathrm{RH} \geq 85 \%$ but without the rain showed that in that case only the moisture indicator related with rain was significantly associated with the rate of ascospore maturation.

The above results confirm that precipitation is the main factor having strongest association with the ascospore development. Let us notice that rain is not only the major factor of ascospore maturation, but it is also responsible for causing most of observed ascospore discharges (Alt and Kollar 2010). About $47 \%$ of the hours with observed ascospores occurred during or $1 \mathrm{~h}$ after the rain, and $63 \%$ no later than $2 \mathrm{~h}$ after the previous precipitation. The numbers of trapped ascospores in these hours accounted for an average of $57 \%$ and $77 \%$ of total number of ascospores observed in the season, respectively. On the other hand, we find that $66 \%$ of the rainy hours were followed by an ascospore discharge which occurred in the same or next hour, and in the case of $73 \%$ of rainy hours, a discharge was observed at the latest $2 \mathrm{~h}$ after the rainfall.

The results also suggest that leaf wetness is another important factor leading to the ascospore maturation on rainless hours. Such conclusion agrees with the results of Rossi et al. (2000) as in their model of spore maturation the temperature is accumulated only if the leaf wetness is observed, irrespective of the rain. Again, leaf wetness resulting from dew may result in ascospore releases though they are rarely observed and are less abundant then the discharges following the rain (Stensvand et al. 1998). The presented data seem to confirm these observations. The discharges occurring three and more hours after the previous rainfall accounted for $37 \%$ of all observed ascospores and for about $14 \%$ of observed ascospores, which shows that they were discharges of low intensity. Let us notice that though use of leaf wetness is very important for description of the ascospore maturation, its application in the models leads to some additional variance in models' results due to variability of the sensors from various manufacturers leading to differences in LW measurements. On the other hand, high relative humidity which is not accompanied by the rain seems to have a limited effect on spore development. This result is contradictory to the experimental results by James and Sutton (1982a).

Hence, the effective mathematical models of ascospore development should include the precipitation and leaf wetness, as moisture sources studied. Additional application of high RH in conditions of central Poland seems questionable. Different strength of association of moisture indicators related to different sources of moisture suggests that the models should take into account different significance of these sources. So far, such models have not been proposed. James and Sutton (1982b) and Rossi et al. (1999) examined models limiting ascospore maturation to days with observed rain or high relative humidity, but no distinction between the two sources of moisture was made in their approaches. Our proposal (manuscript in review) is to consider in a model all main sources of moisture, but to relate the amount of the increase in the cumulative temperature, $T_{\text {cum }}$, to the observed source of moisture. In this approach, in each hour, the $T_{\text {cum }}$ increases by the amount of temperature in that hour multiplied by a weight coefficient, different for each source of moisture.

Finally, could one, in view of the observed correlations between the slope of the $L\left(T_{\text {cum }}\right)$ function and the indicators of moisture, find a precise mathematical relationship expressing the rate of the ascospore development as a function of these factors? Unfortunately, the answer is negative because the presented dependencies were obtained for the aggregated data. Moreover, though the calculated Kendall tau-b and the Goodman and Kruskal's Gamma coefficients are statistically significant, their values are small. Still, increase in the weather descriptors related to the moisture lead to increase in the probability of faster ascospore maturation rate.

\section{Conclusion}

In agreement with experimental results of James and Sutton (1982a) and assumptions applied in most of ascospore maturation models introduced in the literature (Massie and Szkolnik 1974; James and Sutton 1982b; St-Arnaud and Neumann 1990; Stensvand 1993; Rossi et al. 1999, 2000), the results of the study demonstrated that moisture accelerates development of the $V$. inaequalis ascospores. Using the field data from central Poland, the statistically significant associations between the probit slope and moisture descriptors were shown for: total rainfall, number and share of rainy hours and average precipitation per hour; number and share of hours with the observed leaf wetness periods; average relative humidity ( $\mathrm{RH})$, share of hours with $\mathrm{RH} \geq 85 \%$ and share of hours with $\mathrm{LW}>0$ but without the rain observed. The comparison of the strength of these associations show that rain is the main source of the ascospore development but leaf wetness also affect their maturation during periods of no precipitation. As suggested by this study, mathematical models of ascospore development should simultaneously take into account various moisture sources. 


\section{Compliance with ethical standards}

Conflict of interest The authors declare that they have no conflict of interest.

Open Access This article is distributed under the terms of the Creative Commons Attribution 4.0 International License (http://creativeco mmons.org/licenses/by/4.0/), which permits unrestricted use, distribution, and reproduction in any medium, provided you give appropriate credit to the original author(s) and the source, provide a link to the Creative Commons license, and indicate if changes were made.

\section{References}

Alt S, Kollar A (2010) Hydrodynamics of raindrop impact stimulate ascospore discharge of Venturia inaequalis. Fungal Biol 114:320-324

Alves SAM, Beresford RM (2013) Evaluation of three models for predicting Venturia inaequalis ascospore release in Southern Brazil. N Z Plant Prot 66:303-307

Beh EJ, Simonetti B, D'Ambra L (2007) Partitioning a non-symmetric measure of association for three-way contingency tables. J Multivar Anal 98:1391-1411

Beresford RM (1999) Validation of an ascospore release prediction model for apple black spot (Venturia inaequalis). In: Proceedings of the 52nd New Zealand plant protection conference, pp $148-152$

Creemers P, van Laer S (2006) Key strategies for reduction of the dependence on fungicides in integrated fruit production. Phytopathology 39:19-29

Gadoury DM, MacHardy WE (1982) A model to estimate the maturity of ascospores of Venturia inaequalis. Phytopathology 72:901-904

Gadoury DM, MacHardy WE, Rosenberger DA (1989) Integration of pesticide application schedules for disease and insect control in apple orchards of the northeastern united states. Plant Dis 73:98-105

Gadoury DM, Seem RC, MacHardy E, MacHardy WE, Rosenberger DA, Stensvand A (2004) A comparison of methods used to estimate the maturity and release of ascospores of Venturia inaequalis. Plant Dis 88:869-874

James JR, Sutton TB (1982a) Environmental factors influencing pseudothecial development and ascospore maturation of Venturia inaequalis. Phytopathology 72:1073-1080

James JR, Sutton TB (1982b) A model for predicting ascospore maturation of Venturia inaequalis. Phytopathology 72:1081-1085

Lacey ME, West JS (eds) (2006) Using a Burkard trap. In: The air spora. Springer, Boston, MA
MacHardy WE (1996) Apple scab biology, epidemiology and management. The American Phytopathological Society, St. Paul

MacHardy WE, Gadoury DM (1985) Forecasting the seasonal maturation of ascospores of Venturia inaequalis. Phytopathology 75:381-385

Massie LB, Szkolnik M (1974) Prediction of ascospore maturity of Venturia inaequalis utilising cumulative degree-days. Phytopathology 64:140

R Core Team (2018) R: a language and environment for statistical computing (Internet). Vienna, Austria. http://www.R-project.org/. Accessed 30 Jan 2018

Rossi V, Ponti I, Marinelli M, Giosuè S, Bugiani R (1999) Field evaluation of some models estimating the seasonal pattern of airborne ascospores of Venturia inaequalis. J Phytopathol 147:567-575

Rossi V, Ponti I, Marinelli M, Giosuè S, Bugiani R (2000) A new model estimating the seasonal pattern of air-borne ascospores of Venturia inaequalis (Cooke) Wint. in relation to weather conditions. J Plant Pathol 82:111-118

Rossi V, Giosuè S, Bugiani R (2007) A-scab (Apple-scab), a simulation model for estimating risk of Venturia inaequalis primary infections. EPPO/OEPP Bulletin 37:300-308

Roubal C, Nicot PC (2016) Apple scab: numerical optimization of a new thermal time scale and application for modelling ascospore release in southern France. Plant Pathol 65:79-91

RStudio Team (2018) RStudio: integrated development for R (Internet). RStudio, Inc., Boston. http://www.rstudio.com/. Accessed 30 Jan 2018

Schwabe WFS, Jones AL, van Blerk E (1989) Relation of degree-day accumulations to maturation of ascospores of Venturia inaequalis in South Africa. Phytophylactica 21:13-16

St-Arnaud M, Neumann P (1990) Évaluation au Québec d'un modèle de prédiction de la période annuelle d'éjection des ascopores du Venturia inaequalis. Phytoprotection 71:17-23

Stensvand A (1993) Apple scab (Venturia inaequalis): on ascospore release, infection, scab warning, and fungicidal control. Dissertation. Agricultural University of Norway

Stensvand A, Gadoury DM, Seem RC, Amundsen T, Falk SP (1998a) Some recent advances in epidemiology of apple scab. Abstract presented at the 7th international congress of plant pathology, 1998, Edinburgh, UK

Stensvand A, Amundsen T, Semb L, Gadoury DM, Seem RC (1998b) Discharge and dissemination of ascospores by Venturia inaequalis during dew. Plant Dis 82:761-764

Stensvand A, Eikemo H, Gadoury DM, Seem RC (2005) Use of a rainfall frequency threshold to adjust a degree-day model of ascospore maturity of Venturia inaequalis. Plant Dis 89:198-202

Publisher's Note Springer Nature remains neutral with regard to jurisdictional claims in published maps and institutional affiliations. 